\title{
La influencia de la esclavitud en la estructura doméstica y la familia en Jamaica, Cuba y Brasil*
}

\author{
Verena Stolcke
}

Durante mediados de la década de 1970, los académicos impugnaron, respecto a Estados Unidos y las Antillas, el planteamiento que relacionaba la actual desorganización de las familias negras con la experiencia de la esclavitud. En contraste con el énfasis anterior - basado casi exclusivamente- en las restricciones que oprimieron a los esclavos, la autora examina y compara, en el caso de Jamaica, Cuba y Brasil, los efectos que la sexualidad y los patrones de formación de pareja tuvieron dentro de las opciones disponibles para que los negros desarrollaran conductas de familia e ideales propios. Durante la esclavitud y desde entonces, en los distintos patrones de formación de pareja y estructuras de composición del hogar, el punto crítico es la jerarquía de género que invistió a los hombres con el papel activo, dominante. La autora concluye que la sexualidad, los patrones de formación de pareja y los tipos de hogar son el resultado de la interacción entre las jerarquías racial-clasistas, los ideales familiares dominantes y la ideología de género.

In the mid-1970s scholars challenged, regarding the United States and the West Indies, the view that traced contemporary disorganization of the Black family to the experience of slavery. By contrast with the earlier, almost exclusive, emphasis on the constraints that had oppressed the slaves, the author examines and compares for Jamaica, Cuba and Brazil the effects that sexuality and mating patterns had for the choices that had been available to Blacks to develop familiar behaviour and ideals of their own. During slavery and thereafter, in the different mating patterns and the household structures the critical point is gender hierarchy which invested men with the active, dominant role. The author concludes that sexuality, mating patterns and household types are the result of the interplay of the racial-class hierarchy, dominant family ideals, and gender ideology.

VERENA STOLCKE: Universidad Autónoma de Barcelona.

Desacatos, núm. 13, invierno 2003, pp. 134-151.

* Este artículo está basado en el capítulo que lleva el título "The Slavery Period and its Influence on Household Structure and
the Family in Jamaica, Cuba, and Brazil", publicado en Elza Berquó y Peter Xenos (eds.), Family Systems and Cultural Change, the Family in Jamaica, Cuba, an 
$\mathrm{Al}$ interior del ingenio la familia era un cuerpo extraño, rechazado por su naturaleza (Moreno-Fraginals, 1978: 42).

La familia era inconcebible para la inmensa mayoría de la población... la familia nuclear prácticamente era inexistente en el contexto de la esclavitud (Patterson, 1967: 9, 167).

El hijo de un esclavo, aunque conociera a su madre, a menudo no sabía quién era su verdadero padre. De hecho, aunque no lo fuera en el sentido biológico, su padre era el patriarca blanco, el señor de los esclavos (Bastide, 1971: 104).

$\mathrm{H}$ ace ya algunos años Ramón Valdés me dijo de modo perentorio: "El problema del parentesco era el padre." Yo prefiero parafrasear a Simone de Beauvoir, pues opino que ni la madre ni el padre nacen sino que se hacen en la vida en sociedad. Este repaso de la controversia histórica que suscitó la familia esclava en las Américas y sus consecuencias familiares una vez abolida la esclavitud no sólo confirma el célebre aunque tardío descubrimiento que debemos a David Schneider de que los sistemas de parentesco y formas familiares son invariablemente fenómenos históricos; muestra además que el imaginario genealógico propio de las sociedades coloniales y poscoloniales en el Nuevo Mundo está asociado a una ideología racial que, como justificación de un orden social profundamente desigual, dio las pautas de formación de parejas y condujo a un abanico de formas familiares que sólo pueden comprenderse teniendo en cuenta los significados simbólicos de género vigentes. Naturaleza y cultura se conjugan en este contexto dando origen a nociones de maternidad y paternidad situadas históricamente.

Estas citas son una muestra de cómo, hasta los años 1970, la mayoría de los estudiosos de la esclavitud en las Américas interpretaba la vida familiar de los esclavos. Su traslado forzado a las plantaciones del Nuevo Mundo había arrancado a los esclavos africanos de su entorno familiar, social y cultural; y la brutalidad de los dueños de esclavos habría frustrado cualquier posibilidad de forjar nuevas relaciones sociales duraderas y una identidad y valores culturales propios. La esclavitud habría destruido las relaciones conyugales y de parentesco dando origen a hogares centrados en la madre con un padre o marginado o ausente, lo cual habría socavado la autoestima del varón negro. Esa inestabilidad conyugal y promiscuidad sexual, así como la disparidad de las tasas de sexo, habría reducido, además, la fecundidad de las esclavas a tal extremo que el descenso constante de su número obligó a los señores de esclavos a depender del tráfico para su reposición. Este legado de desorganización familiar aún marcaría a la familia afroamericana en la actualidad.

En la década de 1970, Gutman —en el caso de América del Norte y Higman —en el de las Indias británicas occidentales - impugnaron la teoría que remontaba la desorganización contemporánea de la familia afroamericana a la experiencia de la esclavitud. Según estos historiadores, además de prestar atención a las múltiples formas de violencia y opresión que habían padecido los esclavos, debía rescatarse también la resistencia y creatividad manifiesta en las conductas e ideales familiares que éstos habían desarrollado en cautiverio. Vínculos y valores familiares eran indicadores más apropiados para descubrir si, a pesar de la dureza de sus vidas, los esclavos habían logrado forjar una identidad y cohesión culturales propias. De este modo, hacia finales de la década de 1970 emergió una imagen nueva, más diferenciada, de la familia esclava en América del Norte y en las Indias británicas occidentales (Gutman, 1975, 1976; Higman, 1975, 1976a, 1976b, 1979).

Apenas existen estudios comparados de la familia esclava. En este artículo me propongo, por lo tanto, comparar aportaciones recientes sobre la familia esclava y sus descendientes en Jamaica, Cuba y Brasil. Para comprender mejor la influencia que la esclavitud ejerció sobre la familia afroamericana es preciso, además, analizar las pautas de formación de parejas y las conductas familiares de la población afro-americana libre en sus interrelaciones con las élites y la población pobre de procedencia europea. La esclavitud fue un sistema de explotación humana extremo que dejó una marca indeleble en las sociedades que se sustentaban con el trabajo esclavo, al igual que en la conducta de los afroamericanos libres. Las sociedades esclavistas dieron origen a jerarquías socio-raciales res- 
paldadas por la coacción y exclusión legales y extralegales destinadas a asegurar la supremacía de la población blanca. Estas discriminaciones sociales influyeron también en las prácticas sexuales y conductas familiares de la población afroamericana libre. Mi propósito es identificar los modos como los esclavos y los afroamericanos libres establecen relaciones de pareja así como los valores y las formas familiares características de esas sociedades estructuradas por criterios de raza y de clase.

Caben algunas advertencias previas. La bibliografía con nuevas teorizaciones sobre la esclavitud y la familia esclava en Estados Unidos es importante. Quienes han estudiado las colonias esclavistas españolas y portuguesas, en cambio, han demorado en actualizar los saberes al respecto. ${ }^{1}$ Para la investigación de la familia esclava en las Américas las aportaciones hechas por Gutman y Higman son hoy imprescindibles. Pero más allá de cuestiones de fuentes y de métodos de análisis, una reinterpretación de la familia afroamericana tiene también importantes implicaciones políticas para la historia y la identidad de la población afroamericana. Las normas morales domide connotaciones morales, las pautas de establecimiento de relaciones de pareja así como las conductas y los valores familiares inciden por lo tanto en el reconocimiento y la identidad sociales. Finalmente, identificar la fina frontera entre la sumisión y la resistencia de los grupos sociales oprimidos constituye una tarea singularmente escurridiza.

La esclavitud en el Nuevo Mundo tampoco fue un fenómeno homogéneo, aunque se le haya tratado de modo indiferenciado o, en el mejor de los casos, en tanto que dos tipos contrastantes. Aunque la esclavitud tuvo rasgos

${ }^{1}$ Hall (1971) enfatiza el efecto desorganizador que tuvo la esclavitud para la familia esclava, mientras que Scott (1985) rechaza esta posición sin ofrecer, no obstante, un estudio sistemático de la familia esclava. Para un análisis demográfico de la esclavitud cubana véase MorenoFraginals (1977). Para una reseña de la cuestión de la familia esclava, con especial énfasis en Hispanoamérica, véase Russell-Wood (1978, 1982) y Schwartz (1985), quienes dedican extensos capítulos a discutir las hipótesis propuestas por Gutman en el caso de Brasil. Para estudios regionales más recientes de la familia esclava en Brasil véase Slenes (1987); del Nero da Costa, Slenes y Schwartz (1987); Metcalf (1987); Ribeiro Fragoso y Garcia Florentino, s.f.; Gutiérrez, s.f. comunes — se recurrió al trabajo esclavo en general donde la tierra era abundante pero la mano de obra escasadestacan igualmente los contrastes. El número de esclavos transportados a América del Norte, por ejemplo, fue muy inferior al contingente que llegó a las colonias españolas y portuguesas. La evolución demográfica de las poblaciones esclavas varió, además, según las regiones. Se calcula que las colonias inglesas de Norteamérica recibieron 399000 esclavos entre 1701 y 1870, mientras que en el mismo periodo el número de esclavos que fueron desembarcados en la América española y portuguesa alcanzó cerca de un millón y tres millones, respectivamente (Russell-Wood, 1982: 171). ${ }^{2}$ A pesar de esta diferencia notable, en la década de 1830 aproximadamente un tercio de la población afroamericana del Nuevo Mundo se encontraba en Estados Unidos, testimonio de un crecimiento que sugiere una dinámica demográfica muy particular posiblemente vinculada con formas familiares específicas (Klein y Engerman, 1984: 208-209). Jamaica, Cuba y Brasil se distinguían además entre sí. Los tres países tenían economías de plantación con grandes dotaciones de esclavos que producían cultivos destinados al mercado internacional, pero su madurez económica y el porcentaje de africanos y de sus descendientes en sus poblaciones variaba. Aunque sus estructuras económicas se asemejaban, las diferentes realidades coloniales influyeron en la fecha y en el modo en que se dio la abolición. Los esclavos fueron liberados en Jamaica en 1833 y en Cuba en 1884. Brasil fue el último país en abolir la esclavitud, en 1888.

\section{LA FAMILIA Y EL PARENTESCO ENTRE LOS ESCLAVOS}

Una dificultad que plantea la comparación de las pautas de establecimiento de relaciones de pareja y los tipos de familia esclava en Jamaica, Cuba y Brasil se debe (aparte de la escasez y diversidad de datos cuantificables sobre el comportamiento familiar de los esclavos) al escaso nú-

\footnotetext{
${ }^{2}$ Russell-Wood (1982: 161) se muestra escéptico acerca de las hipótesis propuestas por Gutman (1976).
} 


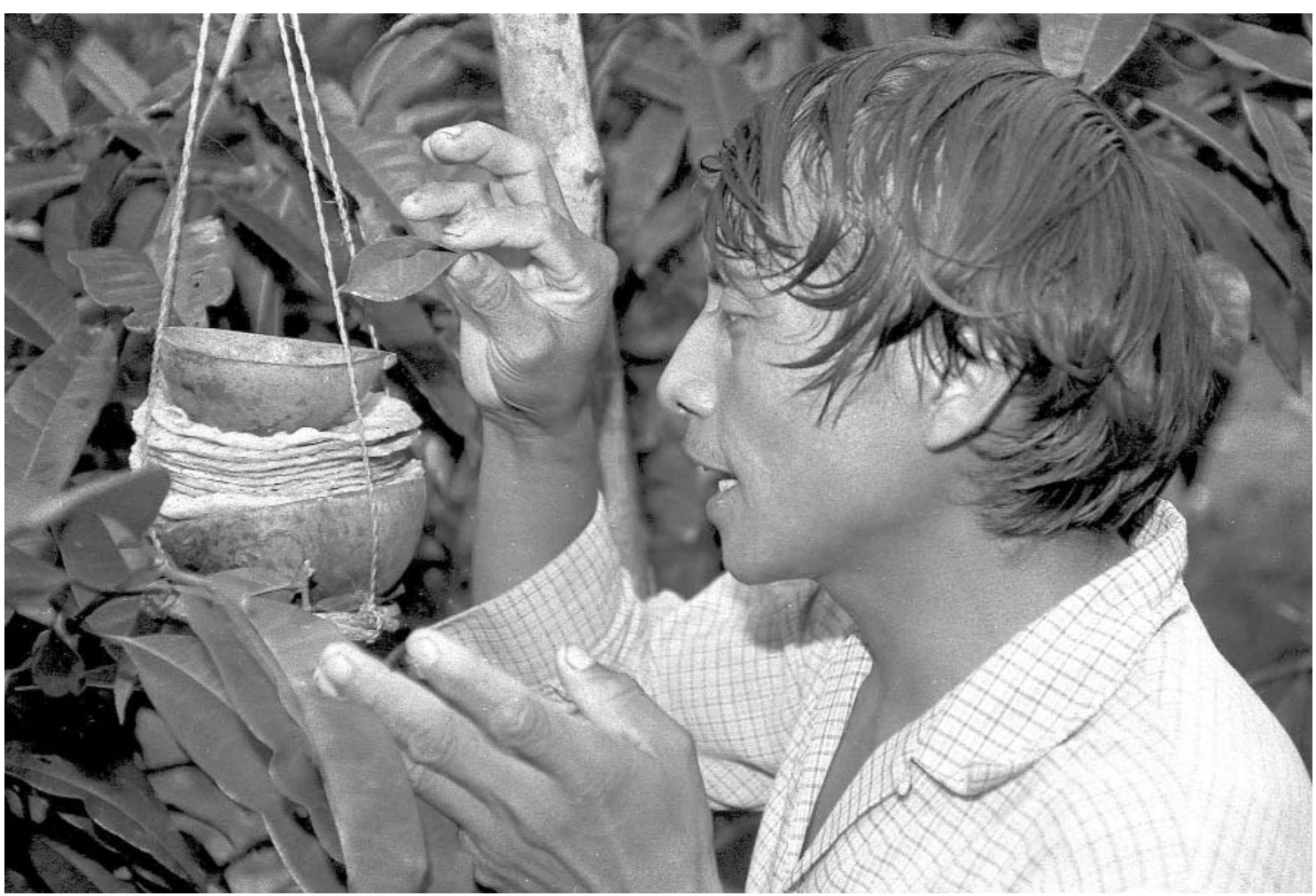

El j’men de Xocén, Alfonso Dzib, reza al "dueño de los venados" para que le permita salir de caza / Christian Rasmussen.

mero de investigaciones disponibles para cada caso. En contraste con los minuciosos análisis cuantitativos de Higman sobre la estructura del hogar esclavo, en especial en Jamaica, aún estamos esperando un estudio de esta naturaleza para Cuba. En Brasil, en cambio, las tesis de Gutman acerca del desarrollo de una cultura familiar afroamericana sí fueron sometidas a examen.

El punto de partida del renovado interés en la familia esclava fue la interrogante acerca de si los esclavos habían sido capaces en cautiverio de constituir familias y mantener lazos de parentesco que les protegiesen de los abusos y la explotación por sus dueños. ${ }^{3}$ Un resultado general de las nuevas investigaciones ha sido la sorpren-

\footnotetext{
${ }^{3}$ Véase Yanagisako (1979) para una útil discusión de las dificultades conceptuales que plantean las nociones de "familia" y "hogar". He optado por traducir "household" por hogar en lugar de emplear el término descriptivo "unidad doméstica".
}

dente diversidad de tipos de hogar esclavo que existía en las tres colonias. En Jamaica, el inestable hogar matrifocal proverbial, compuesto por una mujer con sus hijos e hijas, representaba sólo una de las diversas formas de familia en las plantaciones, sin ser el tipo modal. También existían hogares de familia nuclear integrados por un hombre, una mujer y sus hijos, hogares de familia extensa y unidades domésticas de individuos solteros no emparentados. Higman también halló evidencia de que algunos esclavos privilegiados en cuanto a su ocupación practicaban la poliginia, aunque con los datos disponibles presumiblemente no resultase fácil distinguir la poliginia institucionalizada de la formación de parejas más o menos casuales. Además, una proporción considerable de los hogares estaba compuesta por parientes y la mayoría de esclavos que poseían lazos de parentesco vivían en hogares de familia nuclear. Como Higman concluyó respecto a Jamaica, "aunque menos del $25 \%$ de los escla- 
vos vivían únicamente con parientes identificables, casi el 50\% vivían en hogares próximos a la familia elemental" (Higman, 1976b: 534).

Una parecida diversidad de formas de hogar se ha hallado en Brasil. Los lazos de parentesco se extendían, además, más allá del hogar individual (Schwartz, 1985: 394-406; del Nero da Costa, Slenes y Schwartz, 1987). En Cuba y Brasil, ambos países de tradición católica, los esclavos adoptaron la práctica del apadrinamiento ritual, creando así redes de obligaciones rituales que se extendían más allá del hogar. Los padrinos se adquirían en ocasión del bautismo y el ideal era elegirlos preferentemente entre quienes fuesen de condición social y racial mejor o igual a los padres de la criatura. Los amos, en cambio, no se escogían para apadrinar a un niño (Schwartz, 1985: 406-412; Scott, 1985: 18; Higman, 1979: 45; Russell-Wood, 1982: 164-165).

No obstante, el hecho de que los esclavos hubiesen constituido hogares integrados por familias nucleares y mantenido lazos con parientes no significa que el cautiverio no hubiese afectado las experiencias y las conformay económicos tales como el tamaño de la dotación de esclavos de una plantación o la tasa de sexo, el grado de "criollización" y el tipo de cultivo, así como los abusos sexuales por parte de los administradores y dueños blancos, restringían de modo importante las oportunidades que los esclavos tenían para formar parejas libremente y para conservar lazos de parentesco de modo duradero.

Los cargamentos de africanos destinados a la esclavitud estaban compuestos en cerca del $60 \%$ por varones y comprendían pocos esclavos menores de 20 años (Craton, 1975: 268-269). Mientras duró el tráfico de esclavos siempre hubo un gran exceso de varones que, por lo tanto, carecían de la posibilidad de vivir en hogares familiares (Higman, 1975; Moreno-Fraginals, 1977; Schwartz, 1985). Los esclavos que habían nacido en África, por lo general, tendían a poseer menos parientes que los criollos (Higman, 1975: 276). Pero aunque era menos probable encontrar a africanos en hogares familiares nucleares que a criollos entre los esclavos de plantación que vivían en familias, los africanos que integraban unidades domésticas nucleares alcanzaban un número doble al de los

criollos, entre quienes eran más comunes los hogares encabezados por la madre (Higman, 1979: 52-53). Si se examinan las oportunidades que tenían las esclavas para formar parejas y procrear resulta innegable que el alto índice de masculinidad favoreció su fecundidad.

En las plantaciones de café de la provincia de Sâo Paulo, Brasil, en el siglo XIX, el excedente de varones estaba correlacionado positivamente con el índice de matrimonios entre las esclavas (Slenes, 1987). En Jamaica, una alta tasa de relaciones sexuales estimuló la fecundidad entre la población rural (Higman, 1976a: 120-121). Una razón puede haber sido que cuanto mayor era el déficit de esclavas, mayor el aliciente de los esclavos para entablar relaciones de pareja estables.

Los africanos fueron transportados al Nuevo Mundo para el trabajo forzado en las plantaciones. Además de la tasa de sexo dispar, el tamaño de las propiedades a las que eran vendidos los esclavos desempeñó un papel decisivo para la constitución de la familia esclava. Como la unión con un esclavo de otra plantación o dueño estaba a menudo prohibida, presumiblemente para evitar contenciosos sobre la propiedad de la descendencia esclava, las plantaciones grandes contaban con poblaciones más numerosas para escoger pareja. Las preferencias étnicas en la formación de pareja, señaladas en especial para las grandes plantaciones de Bahía y el Caribe, son un indicio de que los esclavos de ambos sexos gozaban de una cierta libertad para elegir pareja (Schwartz, 1985: 391; Higman, 1979: 55). En las grandes propiedades el riesgo que corrían los esclavos de que su familia fuese separada por la venta era menor que en las pequeñas, aunque las prácticas de los dueños en los diferentes países variaron al respecto (Higman, 1976b: 530, 1979: 50; Slenes, 1987; Schwartz, 1985: 379-412).

En la provincia de Sâo Paulo, que contaba con los índices más altos de matrimonios entre esclavos consagrados por la Iglesia en comparación con cualquier otra región del país, en las propiedades medianas y grandes (con más de nueve esclavos) la mayoría de esclavas estaban casadas cuando habían pasado los 35 años de edad, mientras que en las propiedades pequeñas el porcentaje de matrimonios era muy bajo para ambos sexos. Las madres solteras solían casarse poco después de quedar 
embarazadas, de modo que daban a luz y criaban a sus hijos tras el matrimonio religioso. No obstante, la mayoría de propiedades esclavistas en la provincia de Sâo Paulo eran de tamaño pequeño o mediano (Slenes, 1987; Del Nero da Costa, Slenes y Schwartz, 1987). ${ }^{4}$

Resulta más difícil conocer la estabilidad de las uniones que determinar las pautas de su establecimiento y los tipos de hogar resultantes en un momento concreto. Pero nueva evidencia sugiere que la venta de esclavos y la división de las propiedades por herencia no desembocaban en todas partes, con la frecuencia que se suponía, en la separación de la familia esclava. En las Indias británicas occidentales la mayoría de los hogares esclavos compuestos por familias nucleares parecen haber estado fundados en uniones duraderas (Higman, 1975: 281-283). En Brasil, y dependiendo del momento en el ciclo económico, grupos familiares solían venderse juntos en lugar de separar a sus miembros (Slenes, 1987: 7; Ribeiro Fragoso y García Florentino, 1986: 16; Metcalf, 1987). En las grandes plantaciones de café de São Paulo, por consiguiente, la mayoría de niños crecían en compañía de ambos padres.

El predominio de matrimonios consagrados por la Iglesia entre esclavos no es un buen indicador para identificar los tipos de hogar, ya que se omiten de este modo los hogares constituidos por familias nucleares resultantes de uniones consensuales, pero las diferencias regionales en los índices de matrimonio formal son lo suficientemente importantes para exigir una explicación. La frecuencia del matrimonio formal entre esclavos distingue la provincia de Sâo Paulo de Bahía en Brasil así como de Jamaica y Cuba. En las plantaciones medianas y grandes de la región de Campinas, provincia de Sâo Paulo, en 1872 un $67 \%$ de las esclavas y un $30 \%$ de los esclavos mayores de 15 años habían contraído matrimonio por la Iglesia o habían enviudado (Slenes, 1987: tabla 1, p. 13). En contraste, sólo el 9\% de todas las esclavas en Brasil en 1872 estaban casadas formalmente (Slenes, 1973: 412-420). Los índices de matrimonio formal también eran mucho más

${ }^{4}$ En Bahía en el siglo XVIII, sin embargo, el matrimonio religioso entre esclavos de plantación en la zona de la caña de azúcar parecía ser poco frecuente y los índices de ilegitimidad altos (Schwartz, 1985: 354 ss.). bajos entre los esclavos de plantación en Bahía en el siglo XVIII y en Paraiba do Sul en el siglo XIX (Schwartz, 1985; Ribeiro Fragoso y García Florentino, 1986: 4). En las Indias británicas occidentales, el porcentaje de matrimonios legales era igualmente bajo, aunque las cifras disponibles son escasas, en parte porque los investigadores han estudiado las pautas de formación de relaciones de pareja sin distinguir los matrimonios formalizados. En Cuba sólo el 10\% de las esclavas mayores de 16 años estaban formalmente casadas en 1862 (Martínez-Alier, 1974: 59-60).

Slenes ha atribuido los índices de matrimonio inusualmente altos en las plantaciones de café de Sâo Paulo al poder mayor de la Iglesia aunque ello también puede deberse a motivos económicos, como el tipo de cultivo. Los investigadores han atribuido el carácter selectivo del tráfico de esclavos y el déficit de mujeres al escaso valor económico que supuestamente tenían las esclavas. Éstas realizaban sobre todo labores agrícolas, mientras que los esclavos trabajaban en una gama mayor de ocupaciones. Los índices de participación de las esclavas parecen haber variado de acuerdo con las demandas de mano de obra según cultivo (Mörner, 1980). En Brasil, por ejemplo, el trabajo de los niños y de las mujeres era muy apreciado en las plantaciones de café, especialmente en tiempo de cosecha. Es por esto que los plantadores de café pueden haber visto con mejores ojos que los dueños de otro tipo de plantaciones que sus esclavos formalizasen sus uniones, aunque lo anterior no explique por qué los propios esclavos quisiesen casarse por la Iglesia. Las plantaciones de azúcar cubanas en 1862 tenían un déficit de esclavas mucho mayor que las plantaciones de café (174 y 124 esclavos, respectivamente, por 100 esclavas) (Scott, 1985: 12). En el caso de Brasil, la diferencia en las tasas de sexo de los esclavos es menos clara, por ejemplo, entre las plantaciones de café de Sâo Paulo en la segunda mitad del siglo XIX (188 hombres por 100 mujeres en propiedades con más de nueve esclavos) y en los molinos de azúcar y en las plantaciones de caña de azúcar de Bahía a lo largo del siglo XVIII (cultivos de caña, 126; molinos de azúcar, 199) (Slenes, 1987: 13; Schwartz, 1985: 348). En Jamaica las plantaciones que sólo cultivaban café tenían una tasa de sexo casi equilibrada y experimentaron un crecimiento natural de la población esclava, aunque ésta no era tan 
alta como en las propiedades que combinaban diversas actividades (por ejemplo, el cultivo de pimentón, de café y la cría de ganado) (Higman, 1976a: 121-125). En Paraná, Brasil, donde predominaba la agricultura de subsistencia y la cría de ganado a pequeña y mediana escala para el consumo local, y donde las esclavas desempeñaban, por lo tanto, un papel importante como mano de obra agrícola, las tasas de sexo estaban prácticamente equilibradas a principios del siglo XIX, aunque los índices de masculinidad eran algo más elevados entre los negros que entre los mulatos y los índices de matrimonio formal y de fecundidad aumentaban con el tamaño de las propiedades esclavistas (Gutiérrez, s.f.; Graham, 1976). Esto quiere decir que las variaciones en la demanda de mano de obra, relacionadas con el cultivo, pueden haber influido también en las tasas de sexo, la estructura del hogar y los índices de fecundidad entre los esclavos.

Higman fue el primero en revisar la tesis convencional sobre la fecundidad de las esclavas, según la cual los niveles de crecimiento natural de la población esclava estaban relacionados con las tasas de sexo, la inestabilidad familiar y las pautas de formaciones de uniones informales en el Caribe. Higman puso en entredicho el efecto generalmente negativo que se creía que había tenido la tasa de sexo en la procreación y demostró que las mujeres más fecundas en las propiedades esclavistas jamaicanas eran aquellas que vivían en hogares con una pareja y sus hijos. Les seguían en fecundidad aquellas que vivían en hogares con su descendencia pero sin pareja, mientras que las mujeres que vivían solas o con hombres o mujeres no emparentadas manifestaban una fecundidad muy baja. Además, las criollas tendían a ser más fértiles que las africanas y el mestizaje acrecentó la fecundidad de las mujeres esclavas. Otros factores no demográficos, como el amamantamiento y los tabúes sexuales posparto, así como la interrupción voluntaria del embarazo, pueden haber reducido la fecundidad, pero el principal factor que afectaba a la reproducción esclava era la alta morta-

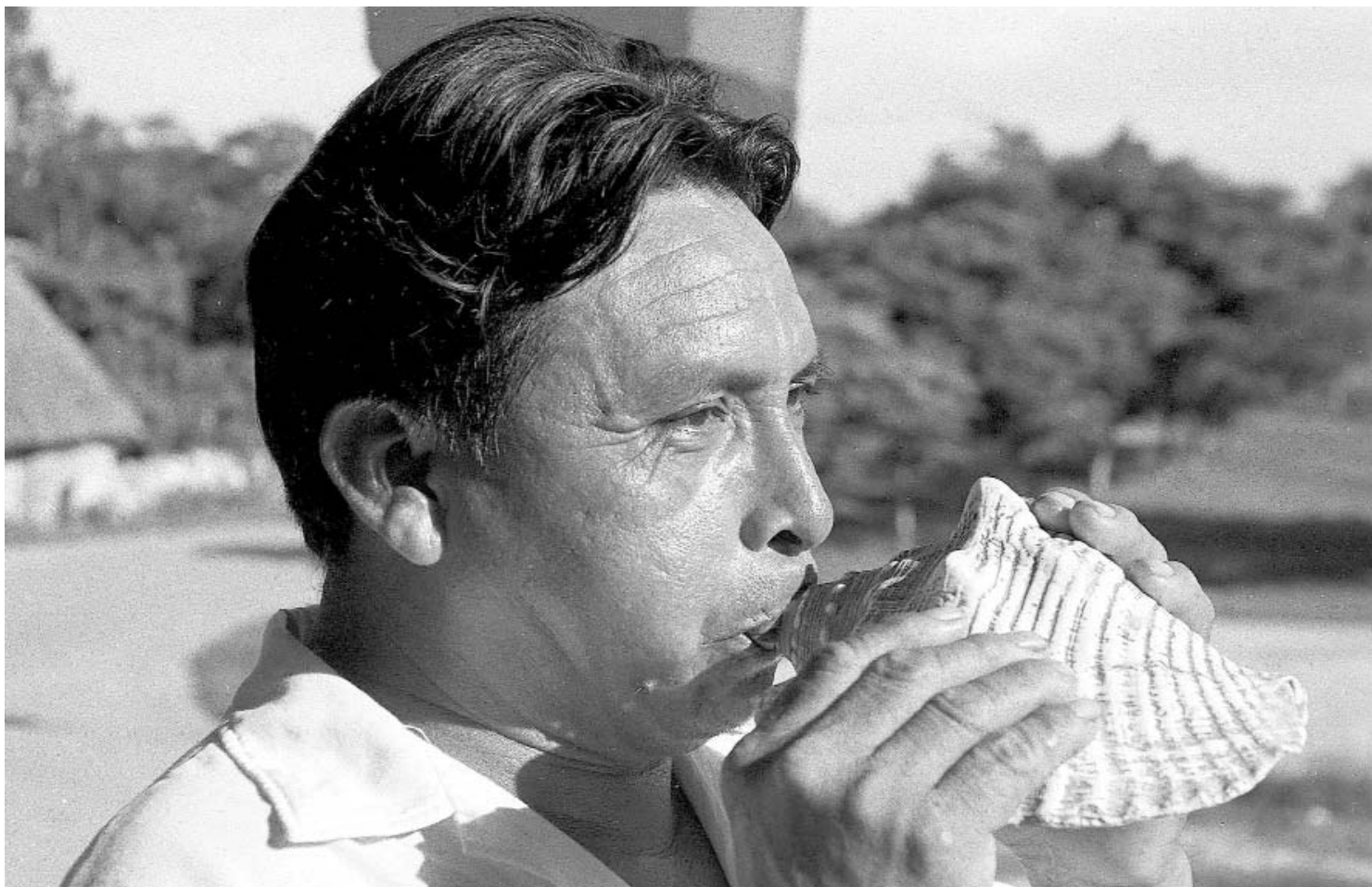

Don Teodoro Canul toca la concha marina tradicional, utilizada para llamar a asamblea. Pueblo de Xocén / Christian Rasmussen. 
lidad infantil, calculada entre el $25 \%$ y el $50 \%$ de todos los nacidos vivos en plantaciones escogidas de Jamaica (Higman, 1976b: 545; 1976a: 115-118). En otras palabras, la inestabilidad matrimonial y las relaciones casuales redujeron la fecundidad, pero las pautas de formación de uniones inestables no eran comunes entre los esclavos.

Por otro lado, en Paraná, Brasil, a principios del siglo XIX las tasas de sexo estaban bastante equilibradas y la población era muy joven debido a un alto índice de natalidad (Gutiérrez, s.f.) - lo que indica un crecimiento vegetativo a pesar de la mortalidad infantil- en contraste con la situación que prevaleció hasta el siglo XVIII en las plantaciones de azúcar en Bahía. Allí predominaban los africanos y el porcentaje de niños era mucho más bajo que entre los criollos esclavos y libres, de modo que la población esclava no se reproducía, sino que se mantenía gracias al tráfico de esclavos (Schwartz, 1985: 349). En el siglo XIX, las plantaciones de café medianas y grandes de Sâo Paulo, en contraste con las propiedades pequeñas, parecían haber proporcionado un ambiente mucho más favorable para las relaciones sexuales regulares en el seno de familias estables consagradas por la Iglesia, como lo indicaba el mayor número de hijos esclavos legítimos, aunque el origen, el color y la condición matrimonial de las esclavas también influían en su fecundidad. Independientemente del tamaño de las propiedades y de las tasas de sexo, las esclavas africanas se casaban más a menudo y eran más fecundas que las mulatas criollas casadas, que eran mas proclives a convertirse en madres solteras y que tenían más hijos que las madres solteras negras (Del Nero da Costa, Slenes y Schwartz, 1987). Nada seguro se sabe sobre la forma de las familias esclavas en Cuba, pero, como en los demás países, la progresiva criollización de la población esclava en las plantaciones mejoró las tasas de sexo y aumentó la proporción de niños en la fuerza esclava (Moreno-Fraginals, 1977: 192; Higman, 1975). Aunque en Cuba el barracón es símbolo de las plantaciones esclavistas, estos auténticos cuarteles sólo se hallaban en los grandes molinos de azúcar, e incluso en ellos no eran desconocidas las unidades de familia esclava (Scott, 1985: 17-20).

Así pues, no cabe duda de que entre la población esclava de aquellos países examinados en los que la revisión de la estructura de la familia esclava está más avanzada prevalecían los hogares de familias nucleares, a parte de otras modalidades domésticas tales como los hogares matrifocales, las familias extensas y los hogares unipersonales de ambos sexos. Esta reinterpretación de los tipos de familia esclava, aunque importante en sí misma, sin embargo presenta algunas dificultades. Está claro que los esclavos lograron crear relaciones sociales y de parentesco propias. Aun así, la influencia que ejercieron respectivamente las tradiciones africanas y las restricciones del cautiverio no están claras (Higman, 1979). Tampoco están completamente explicados el contenido y el significado de estos nuevos vínculos sociales. Los analistas han tendido a extrapolar valores sociales de conductas en su afán por demostrar que los esclavos fueron capaces de influir en las decisiones que afectaban sus vidas, como lo demuestran la realidad y el funcionamiento de la familia esclava. Al sustituir el estudio del matrimonio formal entre esclavos por el análisis de la composición del hogar no lograron descubrir, sin embargo, los motivos que condujeron a los esclavos a optar por un tipo de unión u otro, ni los significados sociales, políticos y simbólicos que estas opciones comportaron para ellos. Es evidente que los hogares son el producto de diferentes tipos de uniones, y que éstos, a su vez, influyen en su composición, su estabilidad y en los derechos y obligaciones mutuos entre quienes la integran; pero las diferencias percibidas (por ejemplo, entre los matrimonios formales y las uniones consensuales) se pasaron por alto. Esta revisión tampoco está exenta, además, de un prejuicio sexista. Nada se menciona sobre la calidad de las relaciones al interior de la familia. Y la cuestión de la jefatura del hogar en tanto que estructura de autoridad, que había ocupado un lugar primordial en las tesis anteriores sobre la posición central de la madre en la familia esclava, perdió relevancia una vez demostrada la existencia de hogares de familia nuclear. Los especialistas dieron por sentado que el hombre era el cabeza de familia omitiendo las consecuencias que ello podía tener para la posición de la mujer o introdujeron la confusa noción de "doble jefatura" sin especificar lo que la misma significaba respecto a las estructuras de autoridad familiar (Russell-Wood, 1982: 181; Schwartz, 1985: 395; Yanagisako, 1979: 178). 
La mayor dificultad de esta revisión reside en determinar la libertad relativa de que disponían los esclavos para escoger sus formas de familia. En su empeño por corregir el énfasis previo en la desorganización de la familia esclava, los historiadores enfatizaron ahora la organización de ésta con el riesgo consecuente de minimizar la opresión extrema propia de la relación amo-esclavo (Russell-Wood, 1982; Gudemann, 1979).

\section{SEXOY RAZA 5}

Según un popular proverbio cubano de aquel entonces, "no hay tamarindo dulce ni mulata señorita". Aunque este dicho sin duda servía de justificación moral de las hazañas sexuales de los hombres blancos, reflejaba también una realidad social. La considerable proporción de mulatos y mulatas en la población de Cuba era con frecuencia fruto de los abusos sexuales a que se veían sometidas las mujeres "de color" por parte de los hombres blancos, rara vez dispuestos a legitimar a los hijos nacidos de estas uniones. ${ }^{6}$ Así, las relaciones sexuales interraciales tenían consecuencias trascendentales para la vida familiar de las esclavas y de las mujeres "de color" libres. El obispo de La Habana, en la década de 1860, denunciaba este estado de cosas en términos concisos:

En todas partes persiste el adulterio y el concubinato, sobre todo entre hombres blancos y mujeres mulatas, produciendo un número excesivo de hijos biológicos, los cuales, a excepción de unos pocos que son reconocidos por sus progenitores, se puede decir que no tienen ni familia ni sociedad, ya que ésta consiste sólo en una madre. ${ }^{7}$

Idealmente, los esclavos debían vivir segregados del mundo de sus amos blancos, pero en la práctica, el sexo interracial desdibujaba constantemente las fronteras

\footnotetext{
${ }^{5}$ La categoría raza es un invento de quienes desarrollaron las doctrinas racistas y carece de cualquier realidad ontológica. He optado, no obstante, por emplear el término sin entrecomillarlo pues en tanto que criterio de clasificación social tenía consecuencias muy reales. ${ }^{6}$ El término descriptivo "de color" era el eufemismo que se empleaba en la Cuba colonial para designar a la población afroamericana.

${ }^{7}$ Martínez-Alier (1974: 125).
}

socio-raciales. ${ }^{8}$ El mestizaje era típicamente el resultado de las relaciones sexuales que mantenían los hombres blancos con esclavas o mujeres "de color" libres. En la sociedad colonial de Bahía, al igual que en la Cuba del siglo XIX, las mujeres "de color" tendían a emparejarse con hombres que eran iguales o superiores a ellas en la jerarquía racial, mientras que los hombres "de color" se emparejaban con mujeres que eran iguales o inferiores a ellos (Schwartz, 1985: 391). En Jamaica los hijos esclavos de padres blancos vivían casi exclusivamente en hogares encabezados por madres, abuelas o tías (Higman, 1976b: 534-536).

Los analistas atribuyeron convencionalmente la frecuencia del mestizaje a la disparidad de las tasas de sexo en la población blanca. Ante la escasez de mujeres blancas, los hombres blancos no tenían otra alternativa que recurrir a las esclavas o a las mujeres "de color" libres para satisfacer sus impetuosas necesidades sexuales (Degler, 1971: 227). No obstante, al menos en la Cuba colonial, esta explicación demográfica no da cuenta del hecho de que la mayoría de estos hombres blancos no estuviesen dispuestos a formalizar sus relaciones sexuales con mujeres "de color" (Martínez-Alier, 1974). Higman (1976a) también ha puesto en tela de juicio la teoría que busca las causas del sexo interracial en la demografía blanca, sugiriendo que al menos en Jamaica la proporción de mestizos en la población esclava se debía a la tasa de sexo entre los esclavos. Cuanto mayor era el exceso de esclavas, en especial en las ciudades, mayor era la población de esclavas y esclavos mestizos. En las zonas urbanas la gran mayoría de los esclavos eran mujeres y también había un porcentaje considerable de hombres blancos y mestizos libres. $\mathrm{Al}$ haber pocos esclavos disponibles, las mujeres esclavas eran más propensas a aceptar a hombres blancos. Ya que la tasa de sexo blanca también estaba más equilibrada en

\footnotetext{
${ }^{8}$ No es nada fácil comprobar la proporción de mulatos en las poblaciones debido a la dinámica de la raza y a la diversidad de categorías raciales. Sin embargo, se ha calculado que en Jamaica, hacia 1832, cerca del 10\% de los esclavos eran mestizos (Higman, 1976a: 142; 1976b: 536). En Bahía nunca hubo más del 10\% de pardos entre los descendientes de africanos en el periodo colonial (Schwartz, 1985: 348-349). En la Cuba del siglo XIX nada menos que el 50\% de la población de color libre podían haber sido mulatos (Knight, 1977: 263-264).
} 


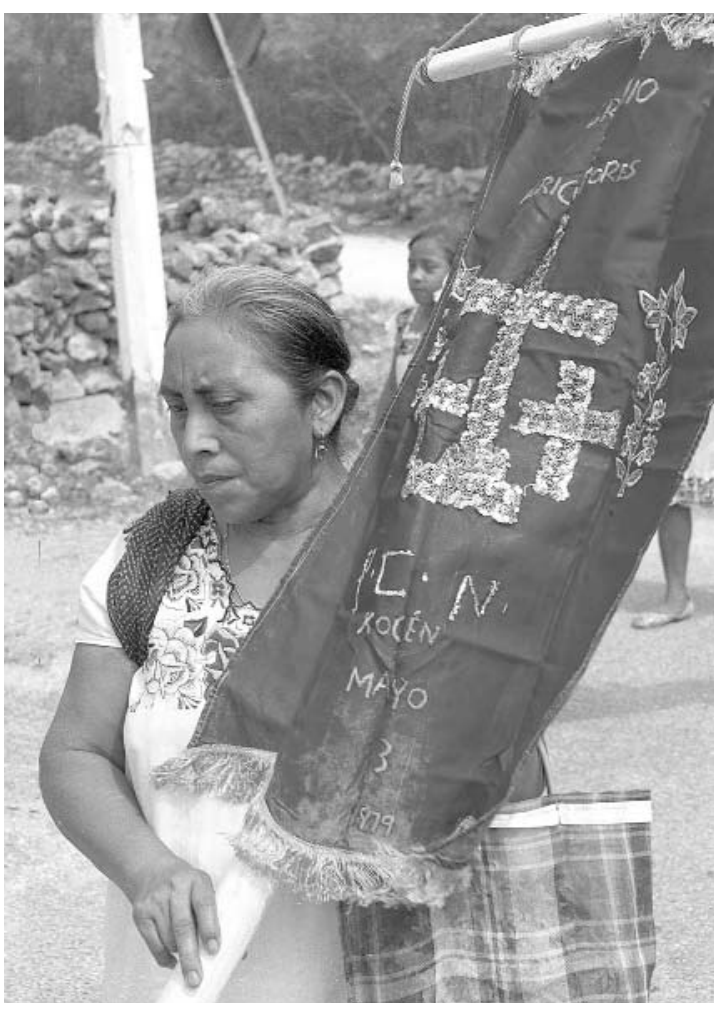

Procesión al santuario de Xocén, "centro del mundo" / Christian Rasmussen.

las ciudades difícilmente pueden atribuirse esas relaciones sexuales a una escasez de mujeres blancas. Los mestizos, por su parte, tendían a unirse con esclavas negras porque perdían ante los blancos en la competencia sexual por las mestizas libres. Como resultado, a finales de la década de 1820 , un $10.7 \%$ de todos los esclavos nacidos en Jamaica habían sido engendrados por hombres blancos que normalmente se recusaban a constituir hogares nucleares con sus parejas "de color" (Higman, 1976a: 143-153). Los hogares formados en torno a una madre eran también más frecuentes en las ciudades donde se concentraba la población mestiza, aunque hogares matrifocales no eran de ningún modo un fenómeno exclusivamente urbano. Las esclavas de las plantaciones estaban igualmente expuestas a agresiones sexuales por parte de los hombres blancos. Pero al vivir la mayoría de hombres blancos en las ciudades, las mujeres "de color" estaban a la merced de las insinuaciones sexuales de un número proporcionalmente mayor de ellos. Entre aquellos esclavos que formaban hogares nucleares en las ciudades predominaban, en cambio, los africanos (Higman, 1979: 50-53).

En consecuencia, los hogares formados en torno a una madre, tanto entre los esclavos como entre la población "de color" libre, fueron en gran medida el producto de relaciones sexuales interraciales. Sin embargo, análisis cuantitativos de este tipo no revelan los procesos y valores sociales que estaban en juego en el sexo interracial, ni las actitudes, deseos u opciones de las mujeres "de color" ante insinuaciones sexuales de hombres blancos, ni tampoco aclaran las posibles diferencias de conducta y experiencia que podían existir entre esclavas y mujeres "de color" libres. No existe ninguna información sistematizada sobre las experiencias de las mujeres esclavas. Tampoco hay estudios para Jamaica o Brasil que se centren específicamente en las relaciones sexuales entre blancos y gente "de color" libre.

\section{“CADA UNO CON SU CADA UNO”}

La esclavitud fue mucho más que un sistema extremo de explotación laboral. Estuvo acompañada de una ideología racial que transcendía el mundo de los esclavos contaminando a todos los sectores sociales, incluyendo a la población afroamericana libre, así como a todos los ámbitos de la vida. De esta manera, la esclavitud también ejerció una profunda influencia en la vida familiar de la gente "de color" libre.

En un estudio sobre las pautas matrimoniales, los ideales raciales y los valores sexuales en la Cuba del siglo XIX he examinado las relaciones de sexo interraciales y sus valores subyacentes (Martínez-Alier, 1974; véase también Ramos, 1975). A diferencia de Jamaica y Brasil, en Cuba el matrimonio interracial se prohibió a partir de 1810, hecho que en sí requeriría un análisis comparado. La introducción masiva de esclavos durante el siglo XIX había intensificado la alarma racista entre la población blanca de la isla. La prohibición del matrimonio interracial reflejaba la hostilidad de los blancos hacia este tipo de unión, pero también fue una prueba de que este antagonismo 
no era compartido por todos los blancos (Martínez-Alier, 1974); hubo algunos hombres blancos en el siglo XIX, por lo general pobres, cuyo deseo de contraer matrimonio con una mujer "de color" era tan impetuoso que procuraron obtener la licencia exigida por el gobierno civil para poder realizarlo. Pero estas eran excepciones contadas. En la mayoría de los casos las relaciones sexuales interraciales consistieron en aventuras fugaces o dieron origen al concubinato más o menos estable pues los hombres blancos rara vez estaban dispuestos a asumir cualquier compromiso social formal.

La población blanca se oponía al matrimonio interracial porque amenazaba el orden esclavista en un doble sentido. Ponía en entredicho el "equilibrio social" y la seguridad pública fundada sobre la segregación de razas. Y socavaba el honor, es decir, la pureza racial de las familias blancas como requisito privado de su preeminencia y relevancia pública. Al ser una sociedad profundamente fragmentada según criterios socio-raciales, en la Cuba del siglo XIX el origen familiar y, sólo en segundo lugar el mérito y los logros individuales, determinaban la condición social de las personas. La intensa ansiedad sobre la pureza racial provocó una auténtica obsesión genealógica. ${ }^{9}$ La endogamia racial y de clase social protegía la jerarquía socio-racial mediante la manutención de la pureza socio-racial familiar de las élites. ${ }^{10} \mathrm{Al}$ depender la condi-

${ }^{9}$ En relación con Brasil, Degler (1971) ha sugerido que el prejuicio racial era simplemente una reacción a las diferencias visibles de color en contraste con Estados Unidos donde era la manifestación de una profunda preocupación acerca del origen genético. Si esta distinción fuese correcta, no se explicaría por qué el mestizaje por lo general ocurriese fuera del matrimonio, sobre todo cuando estaba implicada la clase media o alta. Es más probable que el hecho de que, como en la Cuba del siglo XIX, las relaciones sexuales interraciales fuesen por lo general extra-conyugales, se debiese a que de esta manera se salvaguardaba la exclusividad racial de las élites excluyendo a la descendencia racialmente inferior de sus prerrogativas de clase.

${ }^{10}$ Cabe señalar, no obstante, que ninguna de las tres sociedades estudiadas aquí era monolítica o compuestas por castas. Los ideales raciales de las élites en Cuba fueron desafiados por algunos sectores sociales, como determinados miembros de la Iglesia católica que abogaban por el matrimonio interracial, alegando que todas las personas eran iguales ante Dios independientemente de su raza; algunos criollos progresistas que veían en la integración racial una precondición para la emancipación política de Cuba de la metrópolis; y algunos blancos pobres que deseaban casarse con sus amantes por amor o para tener una mujer que les cuidara (Martínez-Alier, 1974). ción social de los antecedentes genealógico-raciales, el control sexual de las mujeres blancas constituía un pilar fundamental en este edificio ideológico. ${ }^{11}$ Protegiendo la integridad sexual y la formación de parejas de sus mujeres, los hombres blancos pretendían por todos los medios asegurar la pureza socio-racial como requisito de la preeminencia de sus familias. Debido a estos ideales genealógico-raciales las mujeres blancas fueron confinadas a la función de reproductoras de la pureza racial, de tal modo que el sexo informal, y sobre todo interracial, fue el coto de los hombres blancos. Es revelador que el argumento típico empleado para denunciar la amenaza de una rebelión negra era que los negros estaban a punto de violar a mujeres blancas. El matrimonio formal era la norma entre iguales sociales para la población blanca de clase alta, mientras que las uniones y las relaciones sexuales informales extra-conyugales ocurrían típicamente entre desiguales en términos socio-raciales. Las mujeres "de color" eran las víctimas dobles de esa jerarquía de clase y raza. Ellas eran los objetos preferidos en las aventuras sexuales de los hombres blancos. Al eludir éstos cualquier responsabilidad acerca de los frutos de estas relaciones sexuales, ellas a menudo acababan viviendo con sus hijos en hogares sin un hombre. Y aún cuando surgía una unión más duradera, los hombres raramente estaban dispuestos a formalizarla. Pero el tipo de hogar resultante del sexo interracial y la forma institucional que adoptaba dependía también de la condición social del hombre blanco implicado. Los blancos pobres podían llegar a casarse con mujeres "de color", mientras que para los hombres de las élites incluso la cohabitación era inconcebible. No obstante, como el ideal socio-moral imperante era el matrimonio, las uniones consensuales eran tenidas como alternativas de segunda orden y las mujeres "de color" que se avenían a estas uniones extra-conyugales se consideraban faltas de decoro sexual, moral y social. Asimismo, como los hombres blancos en su mayoría no estaban dispuestos a asumir ninguna responsabilidad como marido o pa-

${ }^{11}$ El ideal de la pureza sexual de las mujeres de la clase dominante no se limita a sociedades esclavistas. La moral sexual imperante en la Inglaterra victoriana es otro ejemplo. Ideologías socio-genéticas con consecuencias similares para las mujeres pueden encontrarse también en sociedades que no son abiertamente racistas (Stolcke, 1981). 
dre, el vínculo madre-hijo emergió como el vínculo social primordial.

A pesar de los múltiples abusos a los que estaban sometidas por la sociedad blanca, las mujeres "de color" libres disponían, sin embargo, de algunas alternativas de que hacían buen uso. Cirilo Villaverde en su novela Cecilia Valdés, una condena de la sociedad esclavista cubana, culpa a las propias mujeres "de color" de su desventura. Cecilia, la heroína, es una parda de piel clara, que es cortejada por un joven blanco de buena familia y rechaza a un pretendiente pardo porque, como ella misma admite, "por supuesto que me gustan más los blancos que los pardos... enrojecería de vergüenza si me casara y tuviera por hijo un salto atrás". Su amante blanco, quien, sin que lo sepa la pareja, es también su hermanastro por parte de su padre blanco, acaba casándose con una mujer blanca de su propia clase y abandona a Cecilia con una hija (Villaverde, 1882).

Entre la gente "de color" existía la aspiración de ser claro de piel y de alejarse lo más posible de la esclavitud. Algunas mujeres "de color" trataban de mejorar la suerte de sus hijos mediante el "blanqueamiento" (uniéndose a un hombre blanco) con la esperanza, quizás, de que el padre acabase por formalizar la unión. En el caso de las esclavas en Brasil, por ejemplo, esta estrategia podía mejorar las oportunidades de la madre y sus hijos para lograr la manumisión (Russell-Wood, 1982: 181).

Pero también había mujeres que escogieron afirmar su propia identidad racial. La reacción de una madre parda, que rechazó al pretendiente blanco de su hija cuando pidió su permiso para cohabitar con ella, "ya que su hija era virgen [y] ella [deseaba] que se casase con uno de su propia clase", ejemplifica una forma de resistencia al dominio blanco. No está claro en este caso si la madre se oponía a la unión consensual debido a su inestabilidad, si deseaba el matrimonio (que hubiera sido concebible sólo con un hombre de su propio "color") por razones sociales, o si estaba expresando su rechazo a la supremacía blanca. Probablemente se trataba de una combinación de motivos.

Es difícil saber, retrospectivamente, con qué frecuencia se daban actitudes de resistencia. La mayoría de la gente "de color" seguramente sintió un intenso antagonismo hacia la población blanca pero trataban de adaptarse a su situación lo mejor que podían. Un síntoma de las tensiones latentes en la sociedad cubana era el temor y malestar que la población mulata les inspiraba a los blancos aunque fuesen ellos quienes los engendraban. Al estar más próximos, en términos raciales, de los blancos, se suponía que los mulatos se resentían más de su segregación.

Los valores raciales dominantes contaminaron también a la comunidad "de color". La mayoría de mujeres "de color", si contraían matrimonio, se casaban con parejas de su propio "color" y condición. Las diferencias de "color" y condición legal (estatus libre o esclavo) influyó en las pautas de matrimonio de la población "de color". Predominaba la endogamia de "color" y condición, rechazando los padres a los candidatos o candidatas que consideraban inferiores a sus propios hijos o hijas (Martínez-Alier, 1974: 91).

Finalmente, el concubinato al interior de la misma clase social tenía lugar también entre los sectores más pobres de la sociedad cubana, ya sean blancos pero sobre todo "de color", como en los otros casos estudiados. Por ejemplo, en Vila Rica en Minas Gerais, la capital del distrito minero de oro de Brasil, en 1815 sólo el 21.3\% de la población blanca y aproximadamente el $15 \%$ de la población afroamericana estaba casada. El matrimonio por la Iglesia era una realidad para apenas el $16.6 \%$ de la población mayor de edad y apenas el $32.6 \%$ de los jefes de familia (Ramos, 1975: 209, 218-219). A menudo estas uniones se debían a que la pareja carecía de los recursos para celebrar la boda como era debido. Como no tenían estatus socioeconómico alguno que proteger se ponían a vivir juntos tras fugarse. Al tener hijos y adquirir algunos bienes, o no esperaban mucho para formalizar la unión contrayendo matrimonio, o la unión se disolvía (Figueras, 1907)..$^{12} \mathrm{Al}$ carecer de distinción social el significado

\footnotetext{
12 Según Ramos (1975: 218-219) las mujeres eran las jefas en el 45\% de todos los hogares (el 34.8\% de todos los esclavos vivían en hogares matrifocales). Aunque maridos o padres estuvieran presentes, estos hogares eran percibidos por la comunidad como encabezados por mujeres. Ramos relaciona este fenómeno a un excedente de mujeres así como al desempleo de los hombres. Algo similar se ha encontrado más recientemente entre la población rural pobre de otros lugares del Caribe e Hispanoamérica (Bastien, 1961; Berquó y Loyola, 1984).
} 


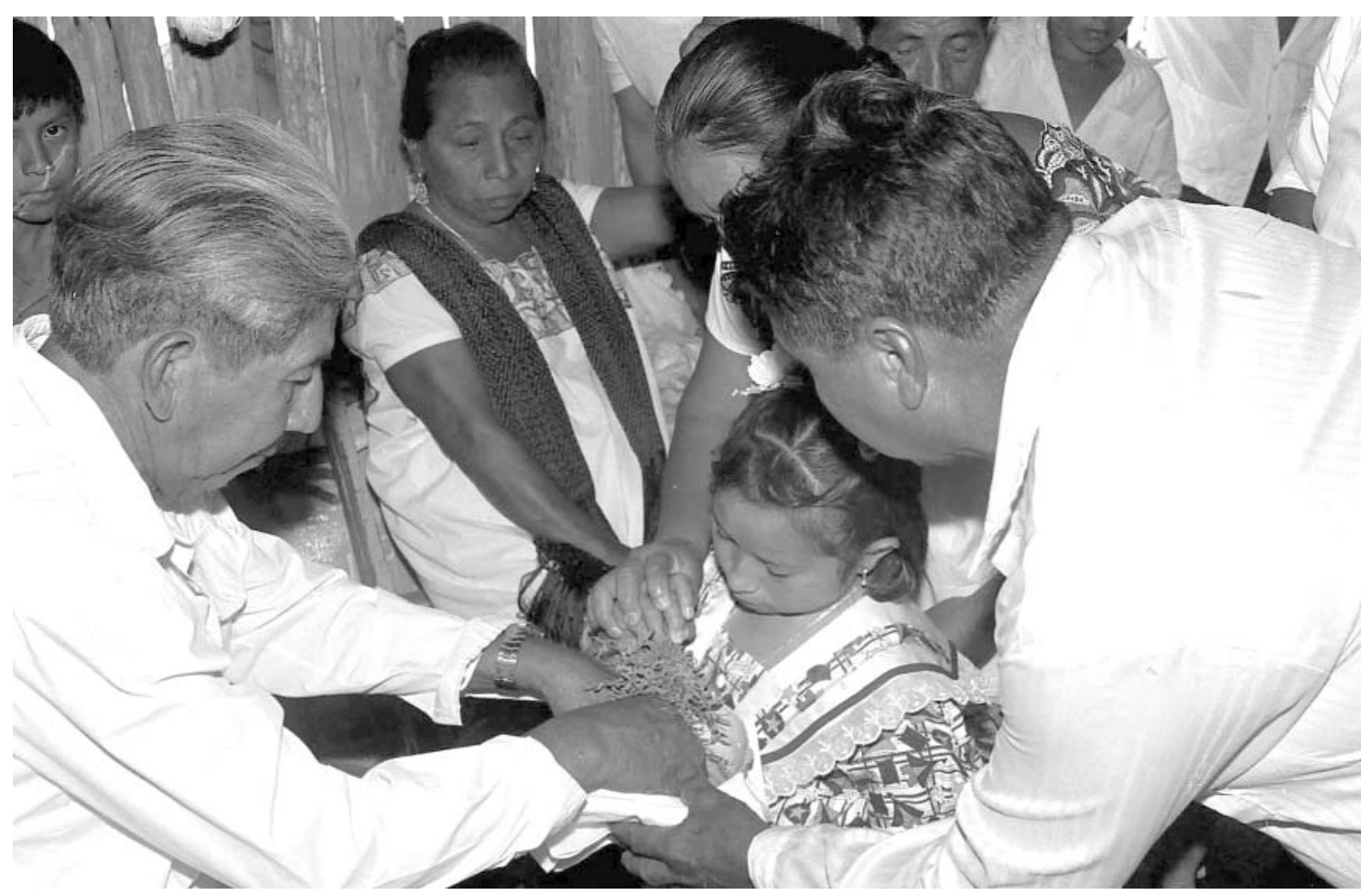

Ceremonia de lavado de manos a los padrinos por sus ahijados / Christian Rasmussen.

simbólico que se le otorgaba al matrimonio formal resultaba menos relevante. Las profundas desigualdades sociales producidas por la esclavitud pueden haber intensificado esta polarización de la formación de uniones según la clase en su intersección con criterios raciales. Es probable, además, que las relaciones sexuales interraciales, al ser en general extra-conyugales, hayan contribuido a erosionar los valores familiares dominantes entre los sectores sociales más bajos. Pero aún así, estos valores sociomorales nunca desaparecieron por completo precisamente debido al significado simbólico que poseían.

\section{LA MATRIFOCALIDAD REVISITADA}

Sin embargo, estructuras familiares similares no tienen necesariamente las mismas causas como bien puede verse al comparar las condiciones que dan origen a hogares matrifocales en distintos contextos sociales históricos.
La mayoría de los estudios sobre la familia afroamericana después del periodo de la esclavitud se realizaron a partir de la Segunda Guerra Mundial. De modo similar a las antiguas investigaciones sobre la familia esclava, privilegiaron la proverbial desorganización familiar característica de la clase baja y en especial la notable preponderancia de los hogares llamados matrifocales, ${ }^{13}$ vista como la causa primordial de todos los males sociales. Inicialmente se realizaron detallados inventarios de tipos de hogar cuyo referente implícito era la familia nuclear occidental. A finales de la década de 1950 este enfoque taxonómico a-histórico dio paso a una perspectiva más dinámica. La familia matrifocal dejó de ser considerada como síntoma de la desorganización social propia

\footnotetext{
${ }^{13}$ El término "matrifocalidad" ha sido empleado para describir situaciones distintas: por un lado, está el hogar en el que la esposa-madre adquiría la autoridad y el control sobre los recursos en algún punto de su ciclo vital mientras que el marido-padre acababa siendo marginado; por el otro, está el hogar sin un varón presente.
} 
de la población afroamericana pobre, atribuyéndose ahora a circunstancias socioeconómicas contemporáneas especialmente adversas.

Smith (1956) y Clark (1957) llevaron a cabo los primeros estudios sobre la organización familiar en la Guyana británica y en Jamaica, respectivamente. Ambos autores atribuyeron la inseguridad económica y la baja valía social de los hombres a las circunstancias socioeconómicas. A causa de su desvalorada identidad racial, que iba unida a un bajo estatus profesional, los hombres acababan marginados a lo largo del ciclo vital de la familia, siendo sus funciones progresivamente asumidas por las esposas-madres (Smith, 1956: 221). Una década más tarde, $M$. G. Smith (1962) discrepó de la perspectiva de sus predecesores al limitarse a estudiar las distribuciones de papeles al interior del hogar. La tipología de formas familiares que desarrolló M. G. Smith en el Caribe tenía, según él, sus antecedentes en la esclavitud. Además, el principio formativo fundamental de la familia y del hogar era el tipo de uniones. La familia matrifocal a menudo resultaba de la falta de voluntad para establecer una familia nuclear estable. Este autor estaba, además, en desacuerdo de que no prevaleciese una distinción normativa entre las formas de unión. De hecho, el matrimonio y el concubinato constituían opciones alternativas que conducían a tipos familiares y de crianza de los hijos formalmente y moralmente distintos. También identificó otra modalidad de uniones, concretamente, la unión extra-residencial, que se parece bastante a la experiencia de Cecilia Valdés. ${ }^{14}$

En la década de 1980 la estructura de autoridad al interior de las familias en el Caribe y en América Latina atrajo renovada atención, esta vez en especial por parte de investigadoras feministas interesadas en la experiencia de las mujeres cada vez más numerosas en los sectores po-

14 Simey ya se había referido en 1946 a los abusos sexuales a que hombres de clase alta sometían a mujeres de clase baja, cuando señaló que en las Indias occidentales "la explotación de las mujeres de los sectores populares por los hombres de clase alta había traído consigo una decadencia general de los principios de conducta, que es ahora parte de una cultura india occidental compartida por la gente de todas las razas. Las clases altas han dado un mal ejemplo que llevará muchas generaciones para borrar, y no es de ningún modo cierto que al extenderse normas de la clase media en la población en general la situación mostrará una tendencia hacia la mejora" (Simey, 1946: 100-101, citado por R. T. Smith, 1982a: 117; véase también R. T. Smith, 1987). pulares de nivel adquisitivo bajo que eran jefas de hogar. Así, en 1970 el 33.8\% de los hogares estaban encabezados por mujeres en Jamaica (Massiah, 1983: 18). ${ }^{15}$ El mismo año hogares de este tipo alcanzaban el 13\% y seguían en aumento, sobre todo en las zonas urbanas, en Brasil (Merrick y Schmink, 1983: 246-248). Varias autoras asociaron este fenómeno con las formas de pobreza provocadas por el desarrollo económico que perjudicó en particular a quienes eran jefas de hogar (Buvinic, Youssef y Elm, 1978; Merrick y Schmink, 1983; Massiah, 1983). No obstante, los procesos económicos no ocurren en un vacío cultural sino que son mediados por valores e ideales sociales. Así, la jerarquía de género convencional junto con la concepción de la familia marcaron las respuestas a la crisis económica de la década de 1980 y sus consecuencias para las familias. ${ }^{16}$

Los análisis de la estructura del hogar en cuanto tal normalmente no llegan a detectar los valores sociales y los significados simbólicos que subyacen a los distintos tipos de hogar. Cuando Rapp, Ross y Bridenthal (1979) criticaron el esencialismo biológico tan común a los estudios convencionales de la familia, señalaron que es preciso distinguir la familia en tanto que fenómeno ideológico (es decir, como ideal relativo a las relaciones con parientes y con quienes no son parientes y a los modos apropiados de reproducir estas relaciones) de las formas de hogar realmente existentes. Esta distinción entre ideología y prácti-

\footnotetext{
${ }^{15}$ Sin embargo, como Youssef y Hetler (1983) han observado, determinar el porcentaje de hogares encabezados por mujeres plantea dificultades por falta de una definición precisa. La jefatura del hogar, como muestran las encuestas oficiales, puede referirse, por ejemplo, tanto a la persona que controla el sustento del mismo como al cabeza de familia identificado por quien realiza la entrevista. La función y la percepción de esa función pueden, no obstante, ser bastante diferentes. Además, los hogares encabezados por mujeres no son necesariamente idénticos, sino que puede tratarse de hogares sin varón presente en el momento (como cuando hubo una deserción, divorcio o defunción), de una unión temporal con un hombre que no proporciona una ayuda económica regular, o de una situación en que debido a la migración estacional el marido se encuentra momentáneamente ausente.

${ }^{16}$ La situación en la Cuba posrrevolucionaria es, por supuesto, bastante diferente. En los primeros años de la revolución, el gobierno llevó a cabo campañas de "matrimonio colectivo" para casar a parejas que habían vivido durante mucho tiempo en concubinato. El divorcio parece haber aumentado notablemente desde entonces, pero el índice de hogares encabezados por mujeres es desconocido. Véase Youssef y Hetler (1983); Stolcke (1984); R. T. Smith (1984).
} 
cas familiares resulta fundamental para poder comprender la interacción dialéctica y dinámica entre ideales familiares dominantes e intereses contradictorios de clase que, más que hechos biológicos, de hecho, dan origen a formas concretas de hogar en la sociedad de clases.

Las pautas de establecimiento de relaciones de pareja constituyen el momento formativo de los diversos tipos de hogar. Se trata, por lo tanto, de identificar las condiciones que dieron lugar a diferentes pautas de unión. Como apuntaba Leach, "de un modo muy fundamental, todos nosotros distinguimos aquellos que son de nuestra categoría de aquellos que no lo son formulándonos la pregunta “' ¿nos casamos con ellos?’” (Leach, 1967: 19). En el Caribe como en Brasil persiste la clasificación social de las personas en "categorías diferentes" que se vio reforzada por el significado sociopolítico con que la esclavitud dotó a las diferencias raciales. El matrimonio legal, en tanto que ideal dominante que regula los derechos recíprocos entre esposos, confiere prestigio social. En la práctica es la forma apropiada de unión entre quienes son iguales con respecto a su clase y "color" y pertenecen a familias mitir a las próximas generaciones. Las relaciones de pareja entre socio-racialmente desiguales, en cambio, suele consistir en uniones sexuales temporales o esporádicas que a menudo tienen como consecuencia a madres solteras que viven en hogares sin un varón presente y en los que los hijos y las hijas carecen de vínculos de parentesco patrilaterales socialmente reconocidos.

Relaciones sexuales esporádicas así como hogares nucleares fundados por un matrimonio legal y con un proyecto de permanencia por supuesto también se dan entre iguales al interior de la clase baja. Aunque las primeras se formalicen más tarde, estas uniones se disuelven con mayor frecuencia, dejando a la mujer como única responsable del sustento de los hijos. ${ }^{17}$ Teniendo en cuenta las condiciones económicas en general adversas, el ideal de estabilidad familiar y decoro social resulta más difícil de conseguir incluso cuando hubo matrimonio. Su papel

${ }^{17}$ En Jamaica el 62.4\% de las mujeres que lideraban un hogar en 1970 no se habían casado nunca; el $18.9 \%$ estaban casadas; el $16.5 \%$ eran viudas; y el 2.2\% estaban divorciadas o separadas (Massiah, 1983: 19).

en tanto que proveedor económico y cabeza de familia convencional se ve amenazado cuando el marido-padre es incapaz de cumplir con sus responsabilidades familiares por el desempleo o la inestabilidad laboral. En tales circunstancias la autoridad doméstica se desplaza a la esposa-madre, que acaba convirtiéndose en cabeza de familia con o sin el marido-padre presente. Uno de los efectos de la grave crisis económica en América Latina en la década de 1980 parece haber sido precisamente éste. Es debido a los valores de género convencionales que las dificultades económicas pueden desorganizar el hogar. El maridopadre literalmente debe ganar su autoridad en el hogar. El lugar natural de la esposa-madre está en la casa. Si un marido-padre no logra cumplir con su papel de proveedor de la familia, se considera que ha perdido su lugar legítimo en la casa. Como bien dice un proverbio brasileño: "Cuando el padre deja la casa, el hogar tiembla; cuando la madre se va, la casa se desmorona." No obstante, las mujeres asumen las responsabilidades de cuidar del hogar y de los hijos no porque el vínculo madre-filial sea el núcleo último e irreducible (biológico) de la familia, sino debido a las nociones culturales de parentesco y a la ideología de género imperantes (Stolcke, 1988: 208-241).

Bien distintas son las causas de las uniones consensuales entre personas del mismo "color" y clase social entre los pobres (por ejemplo, aquellos hogares desde un inicio constituidos al margen de la legalidad) que se daban en la Cuba prerrevolucionaria y que se dan en las Indias occidentales y en Brasil en la actualidad, y que ponen de manifiesto una cierta indiferencia hacia los ideales matrimoniales y familiares dominantes. ${ }^{18}$ La relativa frecuencia de las uniones consensuales de este tipo es un efecto de cómo los sectores pobres perciben la profunda desigualdad de clases. Cuanto mayor y más insuperable pa-

\footnotetext{
18 Berquó y Loyola (1984) han demostrado que en Brasil las uniones consensuales han aumentado notablemente a partir de la década de 1960, no sólo como una alternativa al matrimonio en circunstancias difíciles o inestables, sino también como una opción que se está llegando a institucionalizar. Estas uniones consensuales pueden encontrarse en todas las clases sociales; pero los matrimonios predominan entre las élites, mientras que las uniones consensuales son más frecuentes entre los menos privilegiados. En la Cuba prerrevolucionaria más de un tercio de todas las uniones eran consensuales, según el censo de 1943 (Martínez-Alier, 1974: 140).
} 


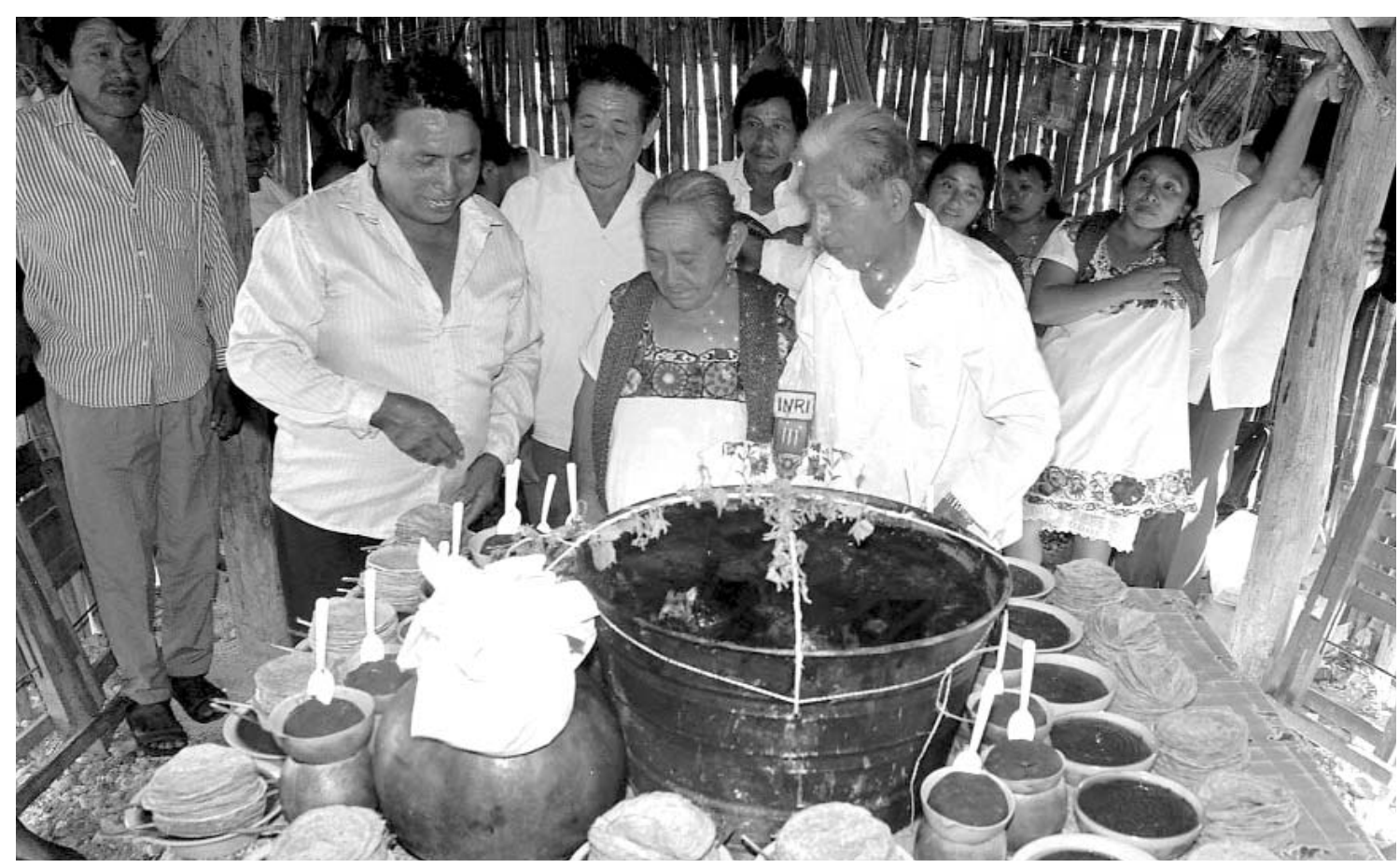

Mesa tradicional con paila con relleno negro y platos con frijol en memoria a Jesús y sus doce apóstoles / Christian Rasmussen.

rece ser la desigualdad social, menos sentido hace para los más desfavorecidos atenerse a las normas familiares decorosas dominantes. Pero, al no estar legalizadas, estas uniones también suelen ser más frágiles y el papel del hombre en ellas menos estable.

Resumiendo, en todas estas diferentes opciones de relaciones de pareja y en las estructuras familiares a que dan lugar, el punto crítico es la relación hombre-mujer, cuyo contenido y estabilidad es una función del grado en el que los implicados y las implicadas están dispuestos a cumplir o son capaces de asumir los derechos y obligaciones recíprocos establecidos por las normas de género y familiares predominantes (R. T. Smith, 1982a). No obstante, como la ideología de género occidental convencionalmente otorga a los hombres el papel activo y dominante, son ellos los que en principio determinan el carácter que tendrá la relación, aun cuando ese privilegio se les pueda volver en contra. ${ }^{19}$ El matrimonio de una pareja socio-

${ }^{19}$ Esta generalización no contempla el nuevo tipo de cohabitación económicamente acomodada establece en principio un vínculo conyugal sólido entre el marido, a quien se le otorga la autoridad doméstica, y la esposa, que está convencionalmente subordinada y en gran medida dependiente de él. Los divorcios que van en aumento en este sector social a menudo son iniciados por la esposa y parecen estar provocando una sensación de fragilidad masculina. Las uniones entre personas del mismo "color" en la clase más baja, en cambio, presentan tres alternativas. Entre ellas estám las relaciones sexuales esporádicas que resultan la mayoría de veces en madres solteras sin un

que ha proliferado en los países industrializados en los últimos años. Aunque se parece en forma a las uniones consensuales discutidas en este artículo, la cohabitación moderna tiene un motivo y significado social y simbólico muy distinto. Las uniones consensuales en América Latina ocurrían haciendo caso omiso de los valores familiares predominantes. La nueva cohabitación en Europa en un inicio era una declaración de rebeldía por parte de ambos contrayentes contra las pautas de formación de parejas vigentes hasta que algunos Estados la equipararan al matrimonio con el fin de regular sus efectos económicos y la condición de los hijos que nacieran (Hopflinger, 1985). 
hombre presente en el hogar. A su vez, incluso en relaciones consensuales estables el vínculo marido-esposa es más frágil que cuando se ha producido el matrimonio, y el hombre, como elemento activo, puede que abandone el hogar. Sin embargo, ni siquiera el matrimonio garantiza necesariamente la estabilidad del mismo, ya que la inseguridad económica, a la que los grupos de bajos ingresos son, por definición, especialmente propensos, puede erosionar la posición del marido dentro del hogar y conducir a la ruptura del vínculo conyugal.

¿Tiene entonces el legado de la esclavitud relevancia para comprender las formas familiares actuales? Como he procurado mostrar, las pautas de establecimiento de relaciones de pareja y los tipos de hogar son el resultado de la interacción dialéctica entre la jerarquía socio-racial, los ideales familiares y la ideología de género vigentes. Las pautas de unión y las formas familiares tienen mucho que ver con la construcción de la identidad social en un denso tejido de relaciones socioeconómicas, y las nociones respecto de la identidad social influyen a su vez en los ideales y el comportamiento familiar. Incluso durante la última instancia con la jerarquía de clases, al justificar la adscripción racial la desigualdad de clases. En el periodo posterior a la abolición de la esclavitud, la relevancia social de la categoría raza así como las formas familiares, más que ser un legado inmediato de la esclavitud, se deben al modo en que las relaciones de clase se han desarrollado bajo circunstancias históricas concretas.

\section{Bibliografía}

Bastide, R., 1971, As religiôes africanas no Brasil, vol. I, Sâo Paulo.

Bastien, R., 1961, "Haitian Rural Family Organization”, Social and Economic Studies, vol. 10, núm. 4, pp. 487-510.

Berquó, E. S. y M. A. Loyola, 1984, "Uniâo de sexos e estrategias reprodutivas no Brasil”, Revista Brasileira de Estudos de Populaçâo, vol. 1, núm. 1/2.

Buvinic, M., N. Y. Youssef y B. Von Elm, 1978, "WomenHeaded Households: The Ignored Factor in Developing Planning", informe presentado a la Office of Women in Development, Agency for International Development, Washington, DC.

Clark, E., 1957, My Mother Who Fathered Me: A Study of the

Family in Three Selected Communities in Jamaica, Allen \& Unwin, Londres.

Craton, M., 1975, “Jamaican Slavery", en S. L. Engerman y E. D. Genovese (eds.), Race and Slavery in the Western Hemisphere, Quantitative Studies, Princeton University Press, Princeton, NJ.

Degler, C. N., 1971, Neither Black nor White: Slavery and Race Relations in Brazil and the United States, Macmillan, Nueva York.

Del Nero da Costa, I., R. W. Slenes y S. B. Schwartz, 1987, "A familia escrava em Lorena (1801)", Revista Estudos Económicos.

Figueras, F., 1907, Cuba y su evolución colonial, repr. 1959, Isla, SA, Habana.

Graham, R., 1976, "Slave Families in a Rural Estate in Colonial Brazil”, Journal of Social History, vol. 9, núm. 3, pp. 382-402.

Gudeman, S., 1979, "Herbert Gutman's The Black Familiy in Slavery and Freedom, 1750-1925", Social Science History, vol. 3, núm. 3/4, pp. 56-65.

Gutiérrez, H. (s.f.), "Demografia escrava numa economía nâo-exportadora: Paraná, 1800-1830”, mimeo.

Gutman, H. G., 1975, Slavery and the Numbers Game: A Critique of Time on the Cross, University of Illinois Press, Urbana, III.

— 1976, The Black Family in Slavery and Freedom, 17501925, Pantheon Books, Nueva York.

Hall, G. M., 1971, Social Control in Slave Plantation Societies: A Comparison of St. Domingue and Cuba, Johns Hopkins Press, Baltimore, Md.

Higman, B. W., 1975, "The Slave Family and Household in the British West Indies, 1780-1834", Journal of Interdisciplinary History, vol. 6, núm. 2, pp. 261-287.

— 1976a, Slave Population and Economy in Jamaica, 18071834, Cambridge University Press, Cambridge y Nueva York.

_ $1976 \mathrm{~b}$, "Household Structure and Fertility on Jamaican Slave Plantations: A Nineteenth Century Example", Population Studies, núm. 27, pp. 527-550.

_ 1979, "African and Creole Family Patterns in Trinidad", en M. E. Crahan y F. W. Knight (eds.), Africa and the Caribbean: The Legacies of a Link, Johns Hopkins University Press, Baltimore, Md.

Hopflinger, F., 1985, "Changing Marriage Behaviour: Some European Comparisons", Genus, vol. 41, núm. 3/4, pp. 41-64.

Klein, H. S. y S. L. Engerman, 1984, "Demografia dos escravos americanos", en M. L. Marcilio (ed.), Populaçâo e Sociedade, Vozes, Petrópolis.

Knight, F. W., 1977, "The Social Structure of Cuban Slave Society in the Nineteenth Century", en V. Rubin y A. Tuden (eds.), Comparative Perspectives on Slavery in New 
World Plantation Societies, New York Academy of Sciences, Nueva York.

Leach, E. R., 1967, "Characterization of Caste and Class Systems”, en A. V. S. De Reuck y J. Knight (eds.), Caste and Race: Comparative Approaches, Little, Brown, Boston.

Martinez-Alier, V., 1974, Marriage, Class and Colour in Nineteenth Century Cuba, Cambridge University Press, Cambridge.

Massiah, J., 1984, La mujer como jefe de familia en el Caribe: estructura familiar y condición social de la mujer, Unesco, París.

Merrick, T. W. y M. Schmink, 1983, "Households Headed by Women and Urban Poverty in Brazil", en M. Buvinic, M. A. Lycette y W. P. McGreevey (eds.), Women and Poverty in the Third World, Johns Hopkins University Press, Baltimore, Md.

Metcalf, A. C., 1987, "Slave Family Life in Eighteenth Century Sâo Paulo: Evidence from Santana de Parnaiba", Revista Estudos Económicos.

Moreno-Fraginals, M. M., 1977, "Africa in Cuba: A Quantitative Analysis of the African Population in the Island of Cuba”, en V. Rubin y A. Tuden (eds.), Comparative Perspectives on Slavery in New World Plantation Societies, New York Academy of Sciences, Nueva York.

__ 1978, El ingenio: complejo económico social cubano del azúcar, vol. II, La Habana.

Mörner, M., 1980, "Buy or Breed? Alternative Sources of Slave Supply in the Plantation Societies of the New World", Memoria, núm. 23, Institute of Latin American Studies, Estocolmo.

Patterson, H. O., 1967, The Sociology of Slavery: An Analysis of the Origins, Development and Structure of Negro Slave Society in Jamaica, MacGibbon and Kee, Londres.

Ramos, D., 1975, "Marriage and the Family in Colonial Vila Rica”, Hispanic American Historical Review, vol. 55, núm. 2, pp. 200-225.

Rapp, R., 1978, "Family and Class in Contemporary America: Notes toward an Understanding of Ideology", Science and Society, vol. 42, núm. 3, pp. 278-300.

Ross, E. y R. Bridenthal, 1979, "Examining Family History", Feminist Studies, vol. 5, núm. 1, pp. 174-200.

Ribeiro Fragoso, J. L. y M. Garcia Florentino, 1986, "Marcelino, filho de Inocencia Crioula, neto de Joana Cabinda: um estudo sobre familias escravas em Paraiba do Sul (1835-1872)", mimeo.

Russell-Wood, A. J. R., 1978, "The Black Family in the Americas”, Societas. A Review of Social History, vol. 8, núm. 1, pp. 1-38.

- 1982, The Black Man in Slavery and Freedom in Colonial Brazil, St Martin's Press, Nueva York.

Schwartz, S. B., 1985, Sugar Plantations in the Formation of
Brazilian Society: Bahia, 1550-1835, Cambridge University Press, Cambridge y Nueva York.

Scott, R. J., 1989, La emancipación de los esclavos en Cuba: La transición al trabajo libre, 1860-1899, FCE, México.

Simey, T. S., 1946, Welfare and Planning in the West Indies, Clarendon Press, Oxford.

Slenes, R. W., 1973, “The Demography and Economics of Brazilian Slavery, 1850-1888”, Ph.D. tesis, Stanford University.

__ 1987, "Escravidâo e familia: padrôes de casamento e estabilidade familiar numa comunidade escrava (Campinas, Seculo XIX)", Revista Estudos Económicos.

Smith, M. G., 1962, West Indian Family Structure, University of Washington Press, Seattle, Washington.

— 1965 , Stratification in Grenada, University of California Press, Berkeley, California.

Smith, R. T., 1956, The Negro Family in British Guiana: Family Structure and Social Status in the Villages, Routledge \& Paul, Londres.

— 1982, "Family, Social Change and Social Policy in the West Indies", New West Indian Guide (Utrecht), vol. 56, núm. 3/4, pp. 111-142.

(ed.), 1984, Kinship Ideology and Practice in Latin America, University of North Carolina Press, Chapel Hill, NC.

_ 1987, "Hierarchy and the Dual Marriage System in West Indian Society”, en J. F. Collier y S. J. Yanagisako (eds.), Gender and Kinship: Essays Towards a Unified Analysis, Stanford University Press, Stanford, California.

Stolcke, V., 1981, "Women's Labours: The Naturalization of Social Inequality and Women's Subordination", en K. Young, C. Wolkowitz y R. McCullagh (eds.), Of Marriage and the Market: Women's Subordination in International Perspective, CSE Books, Londres.

— 1984, "The Exploitation of Family Morality: Labor Systems and Family Structure on Sâo Paulo Coffee Plantations, 1850-1979", en R. T. Smith (ed.), Kinship Ideology and Practice in Latin America, University of North Carolina Press, Chapel Hill, NC.

— 1988, Coffee Planters, Workers and Wives: Class Conflict and Gender Relations on São Paulo Plantations, 1850-1980, St Martin's Press, Nueva York.

Villaverde, C., 1989, Cecilia Valdés o la Loma del Ángel, Cátedra, Madrid.

Yanagisako, S. J., 1979, "Family and Household: The Análisis of Domestic Groups", Annual Review of Anthropology, núm. 8 , pp. 161-205.

Youssef, N. H. y C. B. Hetler, 1983, "Establishing the Economic Condition of Woman-Headed Households in the Third World: A New Approach", en M. Buvinic, M. A. Lycette y W. P. McGreevey (eds.), Women and Poverty in the Third World, Johns Hopkins University Press, Baltimore. 